Research article

\title{
Simple and efficient method for functional RNA extraction from tropical medicinal plants rich in secondary metabolites
}

\author{
Akshara George \\ Department of Plant Biotechnology, College of Agriculture, Vellayani, \\ Thiruvananthapuram-695522, Kerala, India
}

*Corresponding Author: aksharageorge35@gmail.com

[Accepted: 19 January 2018]

\begin{abstract}
Isolation of high-quality functional RNA is prerequisite to facilitate any study related to gene expression and also for downstream applications such as reverse transcription-polymerase chain reaction (RT-PCR), suppression subtractive hybridization (SSH) library construction, differential display (DD), real-time PCR and northern hybridization of medicinal plants. Tropical medicinal plants are rich in polysaccharides, polyphenolics and secondary metabolites that are reported to interfere with the successful RNA isolation. Conventional approaches for the extraction of functional RNA are often time-consuming and need expensive reagents. Moreover, these methods can yield only poor quality and quantity of functional RNA. In our laboratory, we have aimed at establishing a simple and efficient functional RNA extraction procedure. For this, a sodium dodecyl sulfate (SDS) based protocol free of guanidine isothiocyanate was adopted. The total extracted RNA remains in the upper aqueous phase, at acidic conditions leaving DNA and proteins in the lower organic phase. This principle is used in this protocol and the modifications made in the SDS- acid phenol RNA extraction protocol were found to be helpful for extracting RNA from tissues containing large quantities of secondary metabolites. This method can be completed within 3 hours with purity ranges from $1.8-2.0$ as confirmed by $\mathrm{A}_{260 / 280}$ spectrophotometric readings. The above-described RNA extraction protocol works well with all the tissues examined so far, where standard RNA isolation methods failed.
\end{abstract}

Keywords: Functional RNA extraction - Tropical medicinal plants - Polysaccharides Polyphenols - Secondary metabolites - RT-PCR.

[Cite as: George A (2018) Simple and efficient method for functional RNA extraction from tropical medicinal plants rich in secondary metabolites. Tropical Plant Research 5(1): 8-13]

\section{INTRODUCTION}

Tropical medicinal plants have been largely exploited for therapeutic purposes by present-day researchers. Effective conservation and sustainable utilization of plant biodiversity is indispensable for meeting the present and future requirements of medicinal plants. These medicinal plants are rich sources of alkaloids, polyphenols, polysaccharides, secondary metabolites, terpenoids and these phyto compounds have dragged the attention of contemporary researchers. Production of valuable therapeutic compounds from medicinal plants could be made possible through metabolic engineering and recombinant DNA technology (Titanji et al. 2007). The application of modern molecular biology techniques may help in better understanding and conservation of medicinal plants. These tools can unravel the various bioactive compounds with therapeutic significance at the molecular level. Good quality functional RNA extraction is the most important step in gene expression analysis studies (Ghangal et al. 2009). However, RNA extraction from tissues having higher polyphenols, polysaccharides and secondary metabolite contents became a difficult task. The phenolic compounds readily get oxidised to form quinones. These quinones can bind easily with nucleic acids and act as a barrier for good quality RNA isolation (Wang et al. 2008).

Several RNA isolation protocols for medicinal plants has been developed or modified and certain commercial kits were also introduced (John 1992, MacKenzie et al. 1997, Sabir 2012). However, these protocols were found to be incompatible for RNA isolation from majority of medicinal plant species with higher 
polyphenol contents. This is because, the secondary metabolites often co-precipitate with RNA and it affects the yield and quality of RNA (Ghawana et al. 2011). As RNA molecules are subject to degradation by RNases enzymes (Gasic et al. 2004, Hou et al. 2011) several RNA isolation protocols need to be tested and modified. In the present study, three RNA isolation protocols were compared for the production of high-quality RNAs from twelve medicinal plant species. A sodium dodecyl sulfate (SDS) based protocol free of guanidine isothiocyanate was modified and presented in this study. Under acidic conditions, total RNA remains in the upper aqueous phase, leaving DNA and proteins in the lower organic phase. This principle is used in this protocol and the modifications made in the SDS- acid phenol RNA extraction protocol were found to be helpful for extracting RNA from tissues containing large quantities of secondary metabolites. Conventional methods like guanidine$\mathrm{HCl}, \mathrm{CTAB}$ and $\mathrm{LiCl}$ are incorporated in many studies but they failed to extract high-quality RNA from tissues with large quantities of polyphenols, secondary metabolites and polysaccharides. Precipitation of RNA using lithium chloride is not suitable for in vitro translation or reverse transcription based experiments as chloride ions will inhibit protein synthesis and DNA polymerase. While using TRIZOL reagent for RNA extraction, Bilgin et al. (2009) had noticed the presence of organic contaminants in the isolated RNA. The objective of this study was to develop a simple, reliable RNA extraction protocol suitable for a variety of tropical medicinal plants, which meet the quality parameters for further downstream processes.

\section{MATERIALS AND METHODS}

\section{Biological materials}

A total of twelve medicinal plant leaves were collected from the medicinal plant garden of College of Agriculture, Vellayani, Thiruvananthapuram. The leaves were snap- frozen in liquid nitrogen and stored at $80^{\circ} \mathrm{C}$ until use. This study included fresh leaf tissues of the following tropical medicinal plants Centella asiatica (Apiaceae), Aerva lanata (Amaranthaceae), Andrographis paniculata (Acanthaceae), Biophytum sensitivum (Oxalidaceae), Oxalis corniculata (Oxalidaceae), Adhatoda vasica (Acanthaceae), Bacopa monnieri (Bacopa), Azadirachta indica (Meliaceae), Emilia sonchifolia (Asteraceae), Vitex negundo (Lamiaceae), Piper nigrum (Piperaceae) and Zingiber officinale (Zingiberaceae).

\section{Reagents and solutions}

All the glasswares, laboratory apparatus and distilled water used in RNA extraction must be treated with $0.1 \%$ diethyl pyrocarbonate (DEPC) following the standard procedure of Sambrook et al. (1989).

Extraction buffer: $25 \mathrm{mM}$ sodium citrate [pH 7], $25 \mathrm{mM}$ EDTA [pH 8] $40 \mu 1 \beta$ - mercaptoethanol, $1 \%$ SDS and 0.25 g polyvinylpyrolidone (Mr.40,000)

Water-saturated phenol

Isopropanol

$70 \%$ ethanol

Chloroform: isoamyl alcohol $(24: 1 ; \mathrm{v} / \mathrm{v})$

\section{RNA extraction protocol}

$100 \mathrm{mg}$ fresh leaf tissues were ground to fine powder using liquid nitrogen with a pre-sterilized DEPC treated mortar and pestle. $1 \mathrm{ml}$ extraction buffer was added to the samples and ground once more. All the samples were transferred to $2 \mathrm{~mL}$ Eppendrof tubes and $200 \mu \mathrm{l}$ of $2 \mathrm{M}$ sodium acetate, $\mathrm{pH} 4.0,500 \mu \mathrm{l}$ watersaturated phenol, $250 \mu \mathrm{l}$ of chloroform: isoamyl alcohol (24:1) were added to each tube and vortex the samples thoroughly for $1 \mathrm{~min}$. The samples were kept for incubation on ice for $30 \mathrm{~min}$. After incubation samples were centrifuged at $10,000 \times \mathrm{g}$ for $15 \mathrm{~min}$ at $4^{\circ} \mathrm{C}$, the supernatant containing upper aqueous phase was collected carefully into a fresh tube. This upper aqueous phase mostly contains RNA. In to the upper aqueous phase 500 $\mu 1$ water-saturated phenol, $250 \mu 1$ of chloroform: isoamyl alcohol (24:1) were added and mixed by shaking. Samples were centrifuged at $10,000 \times \mathrm{g}$ for $15 \mathrm{~min}$ at $4^{\circ} \mathrm{C}$, and the upper aqueous phase was collected carefully into a fresh tube. In to the upper aqueous layer, $250 \mu 13 \mathrm{M}$ sodium acetate and $750 \mu \mathrm{l}$ ice-cold isopropanol were added and inverted the tubes gently to precipitate RNA. The tubes were kept for 1hour incubation in $-20^{\circ} \mathrm{C}$. To pellet the RNA, centrifuged the tubes at $10,000 \times \mathrm{g}$ for $15 \mathrm{~min}$ at $4^{\circ} \mathrm{C}$ and discarded the supernatant. $500 \mu 170 \%$ ethanol was added to the pellet and centrifuged at $8,000 \times \mathrm{g}$ for $5 \mathrm{~min}$ at $4^{\circ} \mathrm{C}$ and this step was repeated twice to remove the impurities present in the pellet. The pellet was air dried for 10-15 min for removing traces of ethanol. The RNA pellet was dissolved in $50 \mu 1$ of DEPC treated RNase free water. The extracted RNA can be stored at $-20^{\circ} \mathrm{C}$ or $4^{\circ} \mathrm{C}$ until use. 
Quality analysis of RNA

The quality of the isolated RNA was obtained by means of electrophoresis in $1.2 \%$ agarose gels, followed by staining with ethidium bromide $\left(0.1 \mu \mathrm{g} \mathrm{mL} \mathrm{mL}^{-1}\right)$. The purity of the RNA was estimated by calculating the absorbance ratio $\left(\mathrm{A}_{260 / 280}\right)$ and $\left(\mathrm{A}_{260 / 230}\right)$ with a nano drop spectrophotometer (Thermo Scientific NanoDrop ${ }^{\mathrm{TM}}$ 1000).

\section{cDNA synthesis and real-time RT-PCR}

The RNA isolated from leaf samples were subjected to cDNA conversion using Revert Aid FIRST strand cDNA synthesis kit (Thermo scientific, USA). According to the manufacturer's instructions, $0.5 \mu \mathrm{g}$ of RNA was reverse-transcribed to the first-strand cDNA. The reaction conditions comprised of a reverse transcription step at $42^{\circ} \mathrm{C}$ for 1 hour followed by an extension step at $72^{\circ} \mathrm{C}$ for five min. Quantitative real-time PCR (qPCR) was performed with the Eppendroff real plex PCR system (Eppendroff, Hamburg, Germany) in a final volume of 20 $\mu \mathrm{L}$. The reaction mixture consists of $12.5 \mu \mathrm{L}$ of $2 \times$ SYBR green master mix (Fermentas, EU), $0.3 \mu \mathrm{L}$ each of the forward and reverse primers and $5 \mu \mathrm{L}$ of reverse-transcribed cDNA $\left(25 \mathrm{ng} \mu \mathrm{L}^{-1}\right)$. The final volume of the reaction was adjusted with molecular-grade sterile distilled water. Thermal cycling conditions were designed as an initial denaturation at $95^{\circ} \mathrm{C}$ for $30 \mathrm{~s}$, followed by 40 cycles of $95^{\circ} \mathrm{C}$ for $15 \mathrm{~s}, 60^{\circ} \mathrm{C}$ annealing for 1 min and $72^{\circ} \mathrm{C}$ extension for $15 \mathrm{~s}$ and a final extension at $72^{\circ} \mathrm{C}$ for $8 \mathrm{~min}$. The sequences of forward and reverse primers for the catalase gene were 5'- CAGACACTCTACGCTCCGTCAT -3' and 5'TTGAAATCATTTTGCTTGGGAAT - $3^{\prime}$, respectively. The amplified products were resolved in a $1.2 \%$ agarose gel, and photographs were scanned through a Gel Doc System (Alpha imager, Alpha Innotech).

\section{Comparison of RNA extraction methods}

Functional RNA was extracted from the same samples using commercially available kit Ambion Purelink RNA Mini Kit (Life Technologies, USA) and guanidine - $\mathrm{HCl}$ method (Bandyopadhyay et al. 2012). The efficiency of newly developed RNA extraction protocol was compared with the Ambion Purelink RNA Mini Kit and guanidine- $\mathrm{HCl}$ method in terms of purity and yield.

\section{RESULTS}

RNA yield and purity

The yield and purity of the extracted RNA from the twelve different samples were evaluated using a nano drop spectrophotometer (Thermo Scientific NanoDrop ${ }^{\text {TM }}$ 1000) and agarose gel electrophoresis (Fig. 1). RNA yields up to $2212 \mathrm{ng} . \mu \mathrm{l}^{-1}$ from $100 \mathrm{mg}$ of sample material, and in all samples, the $\mathrm{A}_{260 / 230}$ ratio ranged from 2.02 to 2.18, indicating that the RNA was of high purity; free of polyphenol and polysaccharide contamination. Similarly, the $\mathrm{A}_{260 / 280}$ ratio ranged from 1.92 to 2.02 , which also indicated lack of protein contamination. Distinct 28S and 18S ribosomal RNA (rRNA) bands without smearing indicated the integrity of isolated RNA (Fig. 1). This also depicts that the RNA samples were not degraded.

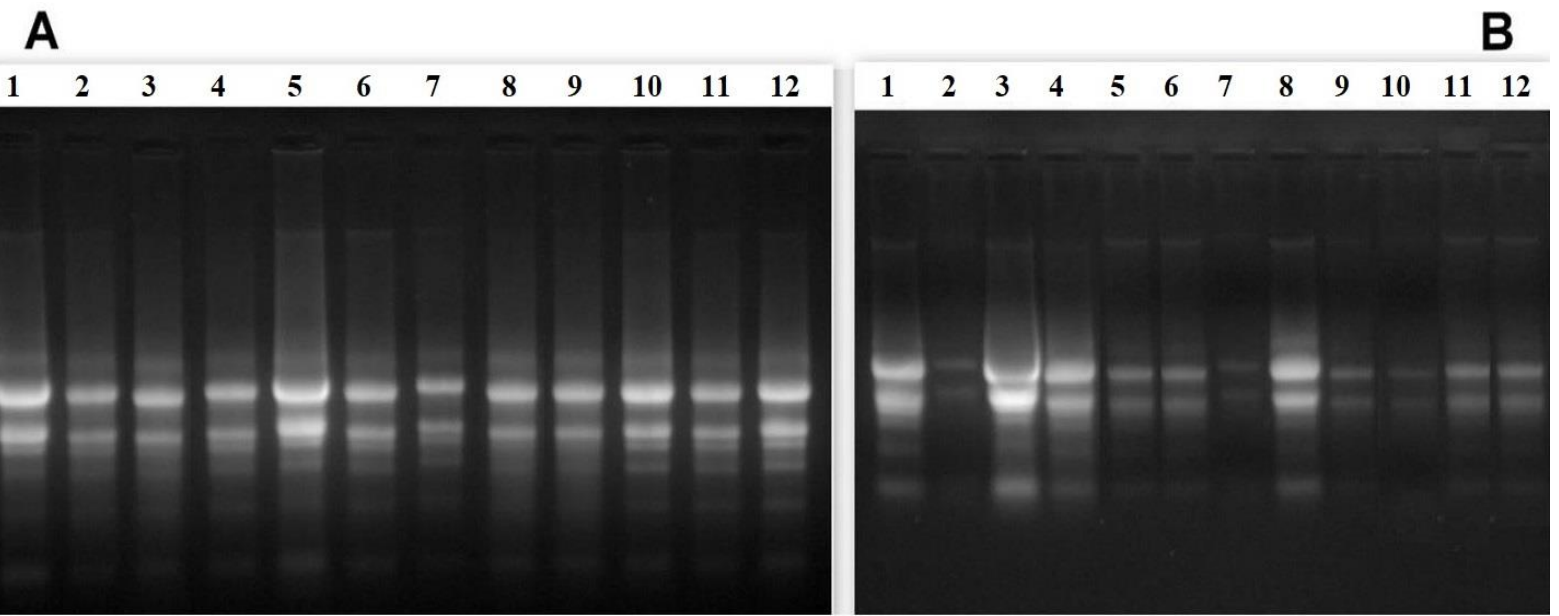

Figure 1. A, Ethidium bromide stained $1.2 \%$ agarose gel of total RNA $(4 \mu \mathrm{g})$ from various plant species extracted with proposed method. Lane 1: Adhatoda vasica; Lane 2: Aerva lanata; Lane 3: Oscimum sanctum; Lane 4: Biophytum sensitivum; Lane 5: Zingiber officinale; Lane 6: Oxalis corniculata; Lane 7: Bacopa monnieri; Lane 8: Azadirachta indica; Lane 9: Emilia sonchifolia; Lane 10: Vitex negundo; Lane 11: Piper nigrum and Lane 12: Centella asiatica; B, Ethidium bromide stained $1.2 \%$ agarose gel of total RNA $(4 \mu \mathrm{g})$ from various plant species extracted with conventional Guanidine $\mathrm{HCl}$ method. 
Quantitative real-time $R T$-PCR

The catalase gene was amplified from the cDNA samples using real-time RT-PCR (Fig. 2). Electrophoresis of amplicons indicated that the primer pair used to amplify the catalase gene fragment exhibited high specificity. The amplification curves demonstrated that these smaller mRNA sequences were largely intact in the RNA samples and that the catalase gene was present in all tissues in moderate abundance.

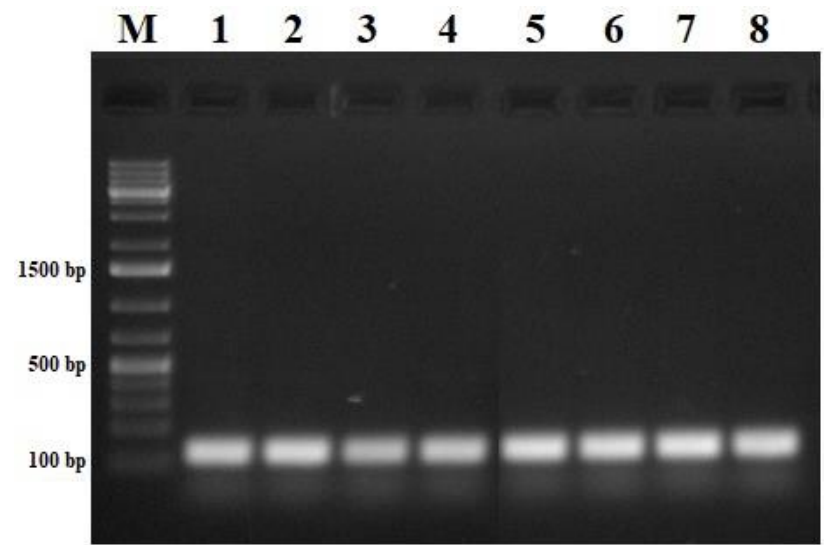

Figure 2. cDNA synthesized from the extracted RNA samples using Revert Aid FIRST strand cDNA synthesis kit (Thermo scientific, USA), Lane M: $1 \mathrm{~kb}$ plus DNA ladder.

\section{Comparison of RNA extraction methods}

Functional RNA from all the leaf samples were obtained by the three protocols tested. Table 1 depicts the purity and yield variations of the total RNA obtained by each method. RNA purity and yield determined by nano spectrophotometry measurements showed that RNA produced by the proposed SDS- acid phenol protocol had a higher purity $\left(\mathrm{A}_{260 / 280}=1.9-2.0\right)$. This extraction method facilitated isolation of large quantities of high-quality RNA from various medicinal plant tissues within in 2-3 hours. Agarose gel electrophoretic analysis showed that when RNA isolated by the guanidine - $\mathrm{HCl}$ method, the two distinct $28 \mathrm{~S}$ and $18 \mathrm{~S}$ ribosomal RNA (rRNA) bands were degraded and not sharp (Fig. 1B). The quantity of RNA extracted using Ambion Purelink RNA Mini Kit, was comparatively higher. Moreover, the purity of the isolated RNA was also higher.

Table 1. Yield and absorbance ratio of total RNA isolated from leaf tissues of medicinal plant species by three methods revealed by Nanodrop spectrophotometer: (A) Proposed method; (B) Ambion Purelink RNA Mini kit; (C) Guanidine- $\mathrm{HCl}$ method.

\begin{tabular}{|c|c|c|c|c|c|c|c|c|c|}
\hline \multirow{2}{*}{ Biological samples } & \multicolumn{3}{|c|}{ Concentration of RNA (ng. $\left.\mu l^{-1}\right)$} & \multicolumn{3}{|c|}{$\mathbf{A}_{260 / 230}$} & \multicolumn{3}{|c|}{$\mathbf{A}_{260 / 280}$} \\
\hline & $\mathbf{A}$ & B & $\mathbf{C}$ & $\mathbf{A}$ & $\mathbf{B}$ & $\mathbf{C}$ & $\mathbf{A}$ & $\mathbf{B}$ & $\mathbf{C}$ \\
\hline Adhatoda vasica & 1203.24 & 1011.75 & 798.84 & 2.08 & 2.22 & 2.46 & 1.89 & 1.99 & 1.78 \\
\hline Aerva lanata & 2012.32 & 1942.22 & 1106.46 & 2.02 & 2.06 & 2.32 & 1.92 & 2.02 & 2.12 \\
\hline Oscimum sanctum & 1998.68 & 1289.98 & 998.98 & 2.09 & 2.14 & 2.40 & 1.96 & 2.08 & 2.08 \\
\hline Biophytum sensitivum & 2212.38 & 2289.68 & 1098.35 & 2.04 & 2.08 & 2.39 & 1.98 & 2.06 & 2.16 \\
\hline Zingiber officinale & 1212.38 & 1243.75 & 926.98 & 2.22 & 2.38 & 2.56 & 1.94 & 2.00 & 2.06 \\
\hline Oxalis corniculata & 1978.25 & 1918.36 & 1046.08 & 2.09 & 2.18 & 2.37 & 1.92 & 2.06 & 1.79 \\
\hline Bacopa monnieri & 2143.42 & 1979.54 & 1008.98 & 2.07 & 2.16 & 2.34 & 1.97 & 1.98 & 2.14 \\
\hline Azadirachta indica & 1208.98 & 956.26 & 698.43 & 2.20 & 2.32 & 2.49 & 1.98 & 1.98 & 2.18 \\
\hline Emilia sonchifolia & 2024.45 & 1758.46 & 1065.96 & 2.05 & 2.08 & 2.32 & 1.94 & 2.02 & 2.19 \\
\hline Vitex negundo & 1437.43 & 1038.28 & 866.98 & 2.18 & 2.26 & 2.44 & 2.02 & 2.04 & 1.68 \\
\hline Piper nigrum & 1282.83 & 1006.98 & 769.94 & 2.14 & 2.24 & 2.46 & 1.94 & 2.06 & 2.18 \\
\hline Centella asiatica & 1884.98 & 1664.28 & 922.28 & 2.03 & 2.08 & 2.32 & 1.98 & 2.02 & 2.14 \\
\hline
\end{tabular}

\section{DISCUSSION}

The purpose of this study was to develop a simple, reliable and efficient RNA extraction protocol suitable for samples rich in secondary metabolites. Moreover, the extracted RNA must meet the quality parameters for downstream processes. The RNA extraction protocol described here is useful for researchers in developing countries with limited laboratory facilities. This procedure is technically easy for isolating high-quality functional RNA even without a column purification steps. The modified SDS- acid phenol extraction method is cost effective and can be completed within 2-3 hours. It can serve as an alternative for expensive kit based RNA extraction methods. The development of a reliable RNA extraction method could find wide application in 
quarantine purposes. Because the only genetic material is moved between countries, this procedure has the advantage of offering a way to eliminate moving organisms across borders, thus safeguarding quarantine regulations, while facilitating pathogen characterization and gene expression analysis studies (Mahuku 2004). In addition, the rapid RNA extraction protocol is beneficial for laboratories that offer RNA analysis services and have depended on the transfer of frozen or lyophilised samples.

For an efficient RNA extraction procedure, we have to reduce secondary chemical reactions including oxidation in the initial crude tissue extract, which otherwise could lead to loss of RNA yield. Phenolic compounds present in the tissue samples readily get oxidised to form quinones (Gehrig et al. 2000, DjamiTchatchou \& Straker 2011). These quinones can bind easily with nucleic acids and act as a barrier for good quality RNA isolation. Polyvinylpyrrolidone (PVP) forms a complex with the polyphenols found in the tissue and helps to get separated from the nucleic acids (Heller \& Ernst 2012). The proposed protocol is a guanidinium salt-free, phenol-based method. It is evident from the researches of Wang et al. (2008), the presence of guanidinium salt stimulates RNA dissociation from the non-protein complex and that will further results in inhibition of successful RNA isolation. Phenol act as a strong protein denaturant and RNase inhibitor. SDS and EDTA used in the extraction buffer are also found to be good RNase inhibitors. Further, pH of the solution was maintained in the acidic range to allow efficient and preferable partitioning of RNA in the aqueous phase leaving DNA in the phenolic phase (Chomczynski \& Sacchi 2006). For maintaining an acidic pH, instead of using buffered phenol, water-saturated phenol was used in the separation step (Chomczynski \& Sacchi 2006). Moreover, incorporation of a resuspension step consisting of ice-cold isopropanol and $3 \mathrm{M}$ sodium acetate resulted in effective precipitation of functional RNA from the contaminating polysaccharides and proteins. Autoclaved DEPC-treated water provided sufficient aqueous environment for the RNA partitioning into the aqueous phase.

The yield of RNA depends on the type of tissue and species used for the extraction procedure. The modified SDS- acid phenol extraction method yielded higher quantities of RNA. The quality of the extracted RNA was found to be higher with an average $\mathrm{A}_{260 / 280}$ of 1.98. But in certain cases like Zingiber officinale the absorption ratio $\mathrm{A}_{260 / 280}$ of the isolated RNA was found to be lower. However, this RNA preparation was suitable for RT PCR. Precipitation of RNA using lithium chloride is not suitable for in vitro translation or reverse transcription based experiments as chloride ions will inhibit protein synthesis and DNA polymerase. The quantity of RNA extracted using Ambion Purelink RNA Mini Kit, was comparatively higher. But commercial kit based RNA extraction is not economical for experiments that demand several RNA extractions. The above-described RNA extraction protocol works well with all the tissues examined so far, where standard RNA isolation methods failed.

\section{CONCLUSION}

The present study aimed to standardize an easy and efficient functional RNA extraction protocol from various tropical medicinal plant tissues rich in secondary metabolites. The rapid and efficient extraction procedure together with the use of easily available chemicals makes this method appropriate for routine RNA isolation which can be used for many downstream molecular works such as Real Time PCR analysis, cDNA library construction, suppression subtractive hybridization ( $\mathrm{SSH}$ ) library construction, differential display (DD) and northern hybridization.

\section{ACKNOWLEDGEMENTS}

The author is grateful to the Director, ICAR- Central Tuber Crops Research Institute, Sreekariyam, Thiruvananthapuram for extending the infrastructure facilities and also thankful to Dean, College of Agriculture, Vellayani, Thiruvananthapuram for the help and support provided throughout the work.

\section{REFERENCES}

Bilgin DD, DeLucia EH \& Clough SJ (2009) A robust plant RNA isolation method suitable for Affymetrix GeneChip analysis and quantitative real-time RT-PCR. Nature Protocols 4: 333-340.

Bandyopadhyay T, Bharalee R, Gohain B, Gupta S, Agarwala N, Singh HR, Chakrabarty S, Bhorali P, Kalita MC \& Das S (2012) Isolation of functional RNA from heavily infested, wilted and necrotic leaf tissues of tea with high polyphenol content. Journal of Agricultural Science and Technology B2: 121-127.

Chomczynski P \& Sacchi N (2006) The single-step method of RNA isolation by acid guanidinium thiocyanate 
phenol chloroform extraction : twenty-something years on. Nature Protocols 1(2): 581-585.

Djami-Tchatchou AT \& Straker CJ 2012) The isolation of high quality RNA from the fruit of avocado (Persea americana Mill.). South African Journal of Botany 78: 44-46.

Gasic K, Hernandez A \& Korban SS (2004) RNA extraction from different apple tissues rich in polyphenols and polysaccharides for cDNA. Plant Molecular Biology Reporter 22: 437a-437g.

Gehrig HH, Winter K, Cushman J, Borland A \& Taybi T (2000) An improved RNA isolation method for succulent plant species rich in polyphenols and polysaccharides. Plant Molecular Biology Reporter 18(4): 369-376.

Ghangal R, Raghuvanshi S \& Chand P (2009) Plant physiology and Biochemistry isolation of good quality RNA from a medicinal plant seabuckthorn, rich in secondary metabolites. Plant Physiology et Biochemistry 47: 1113-1115.

Ghawana S, Paul A, Kumar H, Kumar A, Singh H, Bhardwaj PK, Rani A, Singh RS, Raizada J, Singh K \& Kumar S (2011) An RNA isolation system for plant tissues rich in secondary metabolites. BMC Research Notes 4(85): 1-5.

Heller W \& Ernst D (2012) A simple and efficient protocol for isolation of functional RNA from plant tissues rich in secondary metabolites. Plant Molecular Biology Reporter 18: 33-39.

Hou P, Xie Z, Zhang L, Song Z, Mi J, He Y \& Li Y (2011) Comparison of three different methods for total RNA extraction from Fritillaria unibracteata : A rare Chinese medicinal plant 5(13): 2834-2838.

John ME (1992) An efficient method for isolation of RNA and DNA from plants containing polyphenolics. Nucleic Acids Research 20(9): 2381.

MacKenzie DJ, McLean M A, Mukerji S \& Green M (1997) Improved RNA extraction from woody plants for the detection of viral pathogens by reverse transcription-polymerase chain reaction. Plant Disease 81(2): 222-226.

Mahuku GS (2004) A simple extraction method suitable for PCR- based analysis of plant, fungal, and bacterial DNA. Plant Molecular Biology Reporter 22: 71-81.

Sabir JSM (2012) Abundant high-quality RNA from medicinal plants for molecular applications. Journal of Medicinal Plants Research 6(39): 5214-5221.

Sambrook J, Fritsch EF, Maniatis T \& Cold Spring Harbor Laboratory (1989) Molecular cloning : a laboratory manual, $2^{\text {nd }}$ edition. Cold Spring Harbor Laboratory Press, New York.

Titanji VP, Ngwa AA \& Ngemenya M (2007) Applications of biotechnology techniques to the study of medicinal plants. African Journal of Medical Sciences 36: 23-29.

Wang H, Ghosh A, Baigude A,Yang C, Qiu L, Xia X, Zhou H, Rana TM \& Xu Z (2008) Therapeutic gene silencing delivered by a chemically modified small interfering RNA against mutant SOD1 slows amyotrophic lateral sclerosis progression. The Journal of Biological Chemistry 283(23): 15845-15852. 